\title{
Religion and Health Behaviors in Primary Care Patients
}

\author{
Mina Kang, La Young Park, Seo Young Kang, Jisun Lim, Young Sik Kim* \\ Department of Family Medicine, Asan Medical Center, University of Ulsan College of Medicine, Seoul, Korea
}

Background: Few studies have investigated the association between religion and health behaviors in Korea, where various religions coexist. The present study aimed to investigate the association between religion and health behaviors among primary care patients in Korea.

Methods: We analyzed data from the Family Cohort Study in Primary Care. Among the 1,040 participants in the cohort, 973 of those who had reported their religion were included in the analysis. Participants completed standardized questionnaires that included religious status and lifestyle factors, such as physical activity, smoking status, drinking status, and dietary habits. The association between religion and health behaviors was analyzed using multivariate logistic regression models.

Results: Among the 973 participants, 345 (35.5\%) were Christian, 153 (15.7\%) were Roman Catholic, 308 (31.7\%) were Buddhist, and $163(16.8 \%)$ did not have any religion. Compared with those without a religion, the odds ratio (OR) for vigorous physical activity (OR, 1.52; 95\% confidence interval [CI], 1.01-2.28) increased, and that for binge drinking (OR, 0.67; 95\% CI, 0.46-0.78) and problematic drinking (OR, 0.59; 95\% CI, 0.35-0.99) decreased among participants with a religion. Compared with those without a religion, Catholics were more likely to engage in vigorous physical activity (OR, 2.20; 95\% CI, 1.31-3.67), whereas Christians were less likely to engage in heavy (OR, 0.50; 95\% CI, 0.30-0.84), binge (OR, 0.35; 95\% CI, 0.22-0.54), and problematic drinking (OR, 0.46; 95\% CI, 0.25-0.86). Smoking, meal regularity, and breakfast consumption were not associated with religion.

Conclusion: The status of drinking and physical activities were different according to religion. As religion is one of the psychosocial characteristics of patients, knowing patients' religion can be helpful for primary physicians.

Keywords: Religion; Health Behavior; Exercise; Binge Drinking; Heavy Drinking

Received: July 13, 2018, Revised: November 21, 2018, Accepted: December 11, 2018

*Corresponding Author: Young Sik Kim https://orcid.org/0000-0002-1786-4273

Tel: +82-2-3010-3811, Fax: +82-2-3010-3815, E-mail: youngkim@amc.seoul.kr 


\section{INTRODUCTION}

The World Health Organization defines health as the state of one's physical, mental, and social well-being. ${ }^{1)}$ Since the beginning of recorded history, religion has been related to health and medicine. ${ }^{2,3)}$ Religious beliefs influence human behavior, change cognition, and promote health and well-being. ${ }^{4}$ According to the Census Bureau of the National Statistical Office, in 2015, approximately half of the Korean population reported having a religion, with the most common being Christianity (44.8\%), followed by Buddhism (35.3\%), Catholicism (18.0\%), and Won Buddhism (0.39\%) and Confucianism (0.35\%).

The relation between religion and individual health has been reported. ${ }^{6,7)}$ Frequent participation in religious activities, particularly recent attendance of religious activities, has a significant association with positive physical health outcomes, such as decreases in all causes of cardiovascular and cancer mortality. ${ }^{4)}$ Additionally, such participation has been found to delay adverse health outcomes. ${ }^{8-10)}$ Religion positively influences individual health by motivating healthy behaviors. ${ }^{11)}$ For instance, having a sedentary lifestyle, eating unhealthy food, and excessive drinking and smoking lead to poor health outcomes; however, adherence to religion prevents these by motivating healthy behaviors. ${ }^{12)}$ Further, religious adherence influences mental health by promoting positivity and decreasing anxiety, fear, and depressive moods. Religious adherence ultimately leads to higher life satisfaction and healthy mental status in many populations. ${ }^{13,14)}$

Although the positive influence of religion on health has been investigated, few studies have examined the relation between religion and health in the Korean population. Regardless of religious belief, old people who frequently attend religious services often engage in health promotional activities compared with those without a religion. ${ }^{15)}$ However, the study population in this prior study was restricted to old people. Understanding the religious beliefs of each patient may be helpful for primary physicians because religion is one way of evaluating the psychosocial aspects of a patient. Therefore, the present study investigated the relation between religion and health behaviors of patients who visited primary care clinics in Korea.

\section{METHODS}

\section{Study Participants}

This study analyzed data from the Family Cohort Study in Primary Care (FACTS). FACTS recruited 1,040 couples who visited family physicians for the management of chronic diseases and health examinations. Participants were consecutively enrolled by 28 family physicians in 22 hospitals between April 2009 and June 2011. The study protocol and written informed consent form were approved by the Institutional Review Board of Asan Medical Center (IRB approval no., 2010-0370). The participants read and signed the informed consent form before participation. Among the 1,040 participants in the cohort, 67 who did not respond to the question regarding their religious status were excluded. Thus, 973 participants were included in the analysis.

\section{Data Collection and Measurement}

All participants completed standardized questionnaires that included questions on their age, sex, income, educational level, comorbidities, lifestyle factors, and religious status. Age was divided into four groups: those $<50$ years old, 50-59 years old, 60-69 years old, and $\geq 70$ years old. Household income was categorized into monthly incomes of $<2.00,2.00-3.99,4.00-5.99$, and $\geq 6.00$ million Korean won. Educational level was classified into three groups: $<12,12$, and $>12$ years.

Physical activity was measured with the International Physical Activity Questionnaire (IPAQ) Short-Form, which evaluates the time and intensity of physical activity in the last 7 days. ${ }^{16)}$ According to the IPAQ classification, physical activity was divided into vigorous, minimal active, and inactive. We further categorized physical activity into two groups of either undergoing vigorous physical activity or not. Smoking status was categorized into current smoker and non-smoker. Drinking status was determined by multiplying the number of glasses consumed in one occasion and frequency of alcohol consumed in a weak. The National Institute on Alcohol Abuse and Alcoholism definitions of heavy and binge drinking were used for the analyses. Heavy drinking was defined as 14 glasses of alcohol consumption per week for adult men aged $<65$ years, $>7$ glasses of alcohol consumption per week for adult men aged $\geq 65$ years and adult women aged 65 years, and $>3$ glasses of alcohol consumption per week for adult women aged $\geq 65$ years. Binge drinking was defined as $>4$ glasses of maximum alcohol consumption in one occasion for adult men and $>3$ glasses of maximum alcohol consumption in one occasion for adult women. ${ }^{17)}$ The participants also responded to the Korean version of the Alcohol Use Disorders Identification Test (AUDIT-K); problematic drinking was defined as an AUDIT-K score of $\geq 8 .{ }^{18)}$ Dietary habits were evaluated regarding the following two items: meal regularity and breakfast consumption.

In addition, the participants reported their religious affiliation and status. They were asked whether they had a religion, and then those with a religion chose one of the following: Christian, Catholic, Buddhist, and others.

\section{Statistical Analysis}

Pearson's chi-square test was used to compare the demographic and lifestyle characteristics according to religious status. Multivariate logistic regression was performed to examine the association between religious status and lifestyle factors. In the analysis, we entered religious status as an independent variable and each lifestyle factor as a dependent variable. For the binary logistic regression analysis, all outcome variables were categorized into two groups. Additionally, we adjusted the multivariate model for age, sex, income, education, diabetes mellitus, hypertension, and dyslipidemia. Lastly, multivariate logistic regression analysis was performed with religion type as an independent variable to analyze the relation between religion category and lifestyle characteristics. In this study, $\mathrm{P}<0.05$ was considered statistically significant. All data were analyzed using IBM SPSS Statistics ver. 24.0 (IBM Corp., Armonk, NY, USA). 


\section{RESULTS}

\section{Basic Characteristics of Participants}

Among the 973 participants, 810 reported having a religion and 163 did not. Of the former, 345 were Christian, 153 were Roman Catholic, 308 were Buddhist, and four were of other religions (not shown). Table 1 shows the demographic and lifestyle characteristics according to religious status. The proportion of women was higher than men in all religion categories. Participants with a religion had a higher educational

Table 1. Demographic and lifestyle characteristics of participants according to religious status

\begin{tabular}{|c|c|c|c|}
\hline Characteristic & $\begin{array}{l}\text { Having a religion } \\
\qquad(\mathrm{n}=810)\end{array}$ & $\begin{array}{l}\text { No religion } \\
(n=163)\end{array}$ & P-value* \\
\hline Age (y) & & & 0.139 \\
\hline$<50$ & $156(19.3)$ & $43(26.4)$ & \\
\hline $50-59$ & $277(34.2)$ & $45(27.6)$ & \\
\hline $60-69$ & $290(35.8)$ & $64(39.3)$ & \\
\hline$\geq 70$ & $87(10.7)$ & $11(6.7)$ & \\
\hline Sex & & & 0.010 \\
\hline Men & $387(47.8)$ & $96(58.9)$ & \\
\hline Women & $423(52.2)$ & $67(41.1)$ & \\
\hline Education (y) & & & 0.042 \\
\hline$<12$ & $157(19.5)$ & 46 (28.2) & \\
\hline 12 & $263(32.6)$ & $47(28.8)$ & \\
\hline$>12$ & $386(47.9)$ & $70(42.9)$ & \\
\hline Household income (10,000 Korean won) & & & 0.070 \\
\hline$<200$ & $153(19.4)$ & $25(15.9)$ & \\
\hline 200-399 & $246(31.2)$ & $45(28.7)$ & \\
\hline $400-599$ & $174(22.1)$ & $32(20.4)$ & \\
\hline$\geq 600$ & $215(27.3)$ & $55(35.0)$ & \\
\hline Vigorous physical activity & & & 0.081 \\
\hline Yes & $268(36.1)$ & $43(28.7)$ & \\
\hline No & $474(63.9)$ & $107(71.3)$ & \\
\hline Smoking & & & 0.492 \\
\hline Yes & 85 (11.9) & 21 (13.9) & \\
\hline No & $630(88.1)$ & $130(86.1)$ & \\
\hline Heavy drinking & & & 0.008 \\
\hline Yes & $134(16.8)$ & 41 (25.8) & \\
\hline No & $662(83.2)$ & $118(74.2)$ & \\
\hline Binge drinking & & & $<0.001$ \\
\hline Yes & 310 (38.3) & 87 (53.4) & \\
\hline No & $500(61.7)$ & 76 (46.6) & \\
\hline Problematic drinking & & & 0.040 \\
\hline Yes & $183(42.7)$ & $53(54.1)$ & \\
\hline No & $246(57.3)$ & 45 (45.9) & \\
\hline Regular meal & & & 0.068 \\
\hline Yes & 709 (87.5) & $134(82.2)$ & \\
\hline No & $101(12.5)$ & $29(17.8)$ & \\
\hline Skipping breakfast & & & 0.832 \\
\hline Yes & $186(23.0)$ & 36 (22.2) & \\
\hline No & $623(77.0)$ & $126(77.8)$ & \\
\hline \multicolumn{4}{|l|}{ Comorbidity } \\
\hline Diabetes mellitus & $158(19.5)$ & 29 (17.8) & 0.66 \\
\hline Hypertension & 341 (42.1) & 68 (41.7) & 1.00 \\
\hline Dyslipidemia & $316(39.0)$ & 51 (31.3) & 0.076 \\
\hline
\end{tabular}

Values are presented as number (\%).

${ }^{*} \mathrm{P}$ for trend was calculated for $(2 \times n)$ data. attainment. Meanwhile, those who did not have a religion reported a higher frequency of heavy, binge, and problematic drinking.

\section{Relation between Religious Status and Lifestyle Characteristics}

Table 2 shows the relation between religious status and lifestyle characteristics. In the univariate analysis, the odds ratios (ORs) for heavy (OR, 0.58; 95\% confidence interval [CI], 0.37-0.87), binge (OR, 0.54; 95\% CI, 0.39-0.76), and problematic drinking (OR, 0.63; 95\% CI, 0.410.98 ) were lower among participants with a religion. After adjusting for age, sex, education, income, diabetes mellitus, hypertension, and dyslipidemia, the OR for vigorous physical activity (OR, 1.52; 95\% CI, 1.012.28 ) increased, whereas that for binge (OR, 0.67; 95\% CI, 0.46-0.78) and problematic drinking (OR, 0.59; 95\% CI, 0.35-0.99) decreased among participants with a religion.

\section{Relations between Religion and Lifestyle Characteristics}

Table 3 shows the relation between religious affiliation and lifestyle characteristics. In the multivariate analysis, after adjusting for age, sex, income, diabetes mellitus, hypertension, and dyslipidemia, the OR for vigorous physical activity (OR, 2.20; 95\% CI, 1.31-3.67) increased among Catholics. The ORs for heavy (OR, 0.50; 95\% CI, 0.30-0.84), binge (OR, 0.35; 95\% CI, 0.22-0.54), and problematic drinking (OR, 0.46; 95\% CI, 0.25-0.86) decreased among Christians compared with those of participants without a religion.

\section{DISCUSSION}

This study investigated the relation between religion and health behaviors of patients who visited primary care clinics in Korea. Our findings revealed that participants with a religion were more likely to join vigorous physical activity and less likely to engage in binge and problematic drinking compared with those without a religion. Further, among all participants, Catholics were more likely to engage in vigorous physical activity, whereas Christians were less likely to engage in heavy, binge, and problematic drinking.

Our results showed that religious adherents were more likely to engage in vigorous physical activity than those without a religion, consis-

Table 2. ORs and 95\% Cls for each lifestyle characteristic of the participants with a religion compared with those without a religion

\begin{tabular}{lcc}
\hline \multicolumn{1}{c}{ Outcome variable } & Crude $\mathrm{OR}(95 \% \mathrm{Cl})$ & Multi-adjusted OR $(95 \% \mathrm{Cl})^{*}$ \\
\hline Vigorous physical activity & $1.41(0.96-2.07)$ & $1.52(1.01-2.28)$ \\
Smoking & $0.84(0.50-1.40)$ & $1.10(0.62-1.96)$ \\
Heavy drinking & $0.58(0.37-0.87)$ & $0.65(0.42-1.01)$ \\
Binge drinking & $0.54(0.39-0.76)$ & $0.67(0.46-0.78)$ \\
Problematic drinking & $0.63(0.41-0.98)$ & $0.59(0.35-0.99)$ \\
Irregular meal & $0.66(0.42-1.04)$ & $0.78(0.47-1.29)$ \\
Skipping breakfast & $1.05(0.70-1.57)$ & $1.19(0.76-1.87)$ \\
\hline
\end{tabular}

$\mathrm{OR}$, odds ratio; $\mathrm{Cl}$, confidence interval.

${ }^{*}$ Age, sex, education, income, diabetes mellitus, hypertension, and dyslipidemia were adjusted for in the multivariate analyses. 
Table 3. ORs and 95\% Cls for each lifestyle characteristic of the participants according to their religion

\begin{tabular}{|c|c|c|c|c|}
\hline \multirow{2}{*}{ Variable } & \multicolumn{4}{|c|}{ Religion } \\
\hline & No religion & Christian & Catholic & Buddhist \\
\hline \multicolumn{5}{|l|}{ Crude OR $(95 \% \mathrm{Cl})$} \\
\hline Vigorous physical activity & 1.00 & $1.13(0.74-1.73)$ & $2.13(1.31-3.46)$ & $1.45(0.94-2.22)$ \\
\hline Smoking & 1.00 & $0.60(0.33-1.10)$ & $0.61(0.29-1.29)$ & $1.24(0.71-2.17)$ \\
\hline Heavy drinking & 1.00 & $0.46(0.29-0.73)$ & $0.84(0.50-1.42)$ & $0.61(0.38-0.96)$ \\
\hline Binge drinking & 1.00 & $0.32(0.22-0.48)$ & $0.74(0.47-1.15)$ & $0.78(0.53-1.14)$ \\
\hline Problematic drinking & 1.00 & $0.52(0.31-0.87)$ & $0.81(0.46-1.44)$ & $0.64(0.39-1.04)$ \\
\hline Irregular meal & 1.00 & $0.52(0.31-0.89)$ & $0.54(0.28-1.04)$ & $0.87(0.53-1.45)$ \\
\hline Skipping breakfast & 1.00 & $1.18(0.76-1.84)$ & $0.78(0.45-1.36)$ & $1.03(0.66-1.63)$ \\
\hline \multicolumn{5}{|l|}{ Multi-adjusted OR $(95 \% \mathrm{Cl})^{*}$} \\
\hline Vigorous physical activity & 1.00 & $1.32(0.84-2.07)$ & $2.20(1.31-3.67)$ & $1.46(0.73-2.29)$ \\
\hline Smoking & 1.00 & $0.75(0.38-1.49)$ & $0.84(0.37-1.91)$ & $1.50(0.79-2.82)$ \\
\hline Heavy drinking & 1.00 & $0.50(0.30-0.84)$ & $0.97(0.54-1.73)$ & $0.70(0.42-1.16)$ \\
\hline Binge drinking & 1.00 & $0.35(0.22-0.54)$ & $0.95(0.58-1.57)$ & $1.10(0.71-1.68)$ \\
\hline Problematic drinking & 1.00 & $0.46(0.25-0.86)$ & $0.80(0.41-1.58)$ & $0.60(0.34-1.07)$ \\
\hline Irregular meal & 1.00 & $0.59(0.33-1.06)$ & $0.81(0.40-1.64)$ & $0.92(0.53-1.60)$ \\
\hline Skipping breakfast & 1.00 & $1.18(0.72-1.95)$ & $0.93(0.50-1.72)$ & $1.35(0.81-2.24)$ \\
\hline
\end{tabular}

$\mathrm{OR}$, odds ratio; $\mathrm{Cl}$, confidence interval.

*Age, sex, education, income, diabetes mellitus, hypertension, and dyslipidemia were adjusted for in the multivariate analyses.

tent with a study by Schlundt et al. ${ }^{11)}$ that reported how religion positively affects health by promoting healthy behaviors. Schlundt et al. ${ }^{11)}$ further suggested that religious involvement leads people to practice a healthy lifestyle, with the frequency, intensity, and duration of physical activity of religious people being higher compared with people without a religion. Indeed, religious groups should be considered as communities of people with a similar cultural background. People in the same religion engage in similar activities, such as church sports leagues, which contribute to an increase in physical activity. ${ }^{11)}$ Moreover, a wide range of healthy behaviors, especially walking and strenuous exercise, has been associated with regular attendance in religious activities. A cross-sectional study reported increased odds of walking (1.74 times; 95\% CI, 1.23-2.48) and engaging in strenuous exercise (1.48 times; 95\% CI, 1.02-2.16) among those with attendance of more than once a week compared with those with sporadic and non-attendance. Regular attendance in religious activities has also been associated with regular vitamin intake, infrequent bar attendance, sound sleep quality, never having been a smoker, and abstaining/moderate drinking. ${ }^{19)}$ The particular reason for the increase in physical activity among Catholics has not been investigated, and as such, further study will be needed to identify the differences in physical activity among people of various religious affiliations.

Our study showed that people with a religion were less likely to engage in binge and problematic drinking than those without a religion, and this finding was consistent with previous studies. ${ }^{20-22)}$ Further, Christians were less likely to engage in heavy, binge, and problematic drinking compared with participants without a religion. Religion has been recognized to play an important role in alcohol prevention owing to proscriptive norms regarding alcohol. ${ }^{21)}$ In many religions, people are instructed to avoid alcohol. For instance, in Christianity, many denominations prohibit the consumption of alcohol and promote absti- nence. ${ }^{22)}$ The Catholic doctrine is considered tolerant of heavy drinking. However, according to a US national survey, about $25 \%$ of Catholics report their religion encouraging them to refrain from drinking alcohol. ${ }^{23)}$ Buddhism generally restricts alcohol consumption because alcohol blurs the mind and causes heedlessness. ${ }^{23)}$ In general, strong religious commitment results in less alcohol consumption and misuse. ${ }^{20)}$ However, at the individual level, people in each religious group understand the norms of their religion regarding alcohol use differently. ${ }^{20)}$

Overall, the present study found that the health behaviors of participants differed according to their professed religion. Each religious group consists of a community of people who not only share beliefs but also have similar cultural, socioeconomic, and ethnic backgrounds. ${ }^{22)}$ The social norms for prioritizing health promotion, the community's emphasis on health, and various resources of the community can influence health behaviors in each religion group, leading to different health behaviors. ${ }^{22)}$ For instance, in one longitudinal study, Catholics are shown to have a higher likelihood of alcohol use disorders compared with Hindus. This difference can be attributed to the difference in the norms regarding alcohol use in each religion. Hinduism has stronger religious proscriptions regarding alcohol abstinence compared with Catholicism. ${ }^{22)}$ In another cross-sectional study, ${ }^{11)}$ mainline Protestants and Catholics report healthier eating habits compared with Christians. The diversity of the community, local resources, different traditions on eating habits, such as eating fried chicken at church events, all contribute to different eating habits in each religion. ${ }^{22)}$

In our study, a number of lifestyle characteristics were not associated with religious status. For instance, smoking habits were not associated with religion, which was not consistent with previous findings. According to Hill et al., ${ }^{19)}$ people who regularly attend religious service 
are more likely to be non-smokers. In another study, ${ }^{24)}$ and Protestants and Catholics are more likely to be never-smokers. In our study, the proportion of never-smokers was higher in people with a religion (59.3\% in people with a religion versus $55.6 \%$ in people without a religion), indicating the possibility of religious influence on smoking behaviors.

This study has several limitations. First, because of the nature of cross-sectional analyses, the causal relation between the study variables could not be established. Second, this study did not consider the frequency of religious attendance and duration of having a religion. Previous studies have reported a higher frequency of attendance in religious functions leading to more positive health outcomes, ${ }^{4,15,25)}$ and that longitudinal attendance of such activities bring beneficial health effects. ${ }^{11)}$ Third, these results may not be generalizable to the entire Korean population. However, our study included a large number of participants who visited primary care clinics in Korea. Further, to the best of our knowledge, this study is the first to investigate the relation between religion and health behaviors among participants who visited primary care clinics. A prospective study considering the association between health outcomes and religious function will be of interest to future research.

In conclusion, people without a religion were found to engage in less physical activity and were more likely to engage in binge, heavy, and problematic drinking. Thus, health behaviors differed according to professed religion. Therefore, when meeting a patient, primary physicians should also consider religion, a psycho-social characteristic of patients.

\section{CONFLICT OF INTEREST}

No potential conflict of interest relevant to this article was reported.

\section{ACKNOWLEDGMENTS}

This research was supported by Korea Centers for Disease Control and Prevention (2011E7400300).

\section{ORCID}

Mina Kang: https://orcid.org/0000-0002-9614-9664

La Young Park: https://orcid.org/0000-0001-9788-9202

Seo Young Kang: https://orcid.org/0000-0002-7177-7816

Jisun Lim: https://orcid.org/0000-0002-7341-4584

Young Sik Kim: https://orcid.org/0000-0002-1786-4273

\section{REFERENCES}

1. World Health Organization. WHO definition of health [Internet]. Geneva: World Health Organization; 2018 [cited 2019 Jan 5]. Available from: http://www.who.int/about/mission/en/.

2. Meng Q, Zhang X, Shi R, Liao H, Chen X. Correlation between religion and hypertension. Intern Emerg Med 2019;14:209-37.

3. Koenig HG. Religion, spirituality, and health: the research and clinical implications. ISRN Psychiatry 2012;2012:278730.

4. Li S, Stampfer MJ, Williams DR, VanderWeele TJ. Association of religious service attendance with mortality among women. JAMA Intern Med 2016;176:777-85.

5. Population and Housing Census of the National Statistical Office by 2015: population by sex, age, and religion [Internet]. Daejeon: Statistics Korea; 2018 [cited 2019 Jan 5]. Available from: http://kosis.kr/ statHtml/statHtml.do?orgId=101\&tblId=DT_1PM1502\&vw_cd=\&list_ $\mathrm{id}=\& \operatorname{scrId}=\&$ seqNo=\&lang_mode $=$ ko\&obj_var_id=\&itm_id=\&conn path=E1.

6. Rippentrop EA, Altmaier EM, Chen JJ, Found EM, Keffala VJ. The relationship between religion/spirituality and physical health, mental health, and pain in a chronic pain population. Pain 2005;116:311-21.

7. Stroope S, Baker JO. Whose moral community?: religiosity, secularity, and self-rated health across communal religious contexts. J Health Soc Behav 2018;59:185-99.

8. Roth DL, Usher T, Clark EM, Holt CL. Religious involvement and health over time: predictive effects in a national sample of African Americans. J Sci Study Relig 2016;55:417-24.

9. Koenig HG, McCullough ME, Larson DB. Handbook of religion and health. New York (NY): Oxford University Press; 2001.

10. Levin J. God, faith, and health: exploring the spirituality-healing connection. New York (NY): Wiley and Sons; 2001.

11. Schlundt DG, Franklin MD, Patel K, McClellan L, Larson C, Niebler S, et al. Religious affiliation, health behaviors and outcomes: Nashville REACH 2010. Am J Health Behav 2008;32:714-24.

12. McIntosh RC, Ironson G, Krause N. Do religious and spiritual identity confer risk for hypertension via psychosocial and lifestyle factors? J Health Psychol 2017:1359105317748733.

13. Caplan LS, Sawyer P, Holt C, Allman RM. Religiosity and function among community-dwelling older adult survivors of cancer. J Relig Spiritual Aging 2013;25:311-25.

14. Sternthal MJ, Williams DR, Musick MA, Buck AC. Depression, anxiety, and religious life: a search for mediators. J Health Soc Behav 2010;51:343-59.

15. Yi Y, Kim J. Religion and health behavior among Korean older adults. Health Soc Sci 2016;43:207-29.

16. International Physical Activity Questionnaire. Guidelines for data processing and analysis of the International Physical Activity Questionnaire (IPAQ): short and long forms [Internet]. [place unknown]: IPAQ; 2005 [cited 2019 Jan 5]. Available from: https://sites.google.com/site/ theipaq/questionnaire_links/IPAQ_Korean_self-admin_short. doc?attredirects $=0 \& \mathrm{~d}=1$.

17. National Institute on Alcohol Abuse and Alcohoilsm. Drinking levels defined [Internet]. Bethesda (MD): National Institute on Alcohol Abuse and Alcohoilsm; 2005 [cited 2019 Jan 5]. Available from: https:// www.niaaa.nih.gov/alcohol-health/overview-alcohol-consumption/ moderate-binge-drinking.

18. Saunders JB, Aasland OG, Babor TF, de la Fuente JR, Grant M. Development of the Alcohol Use Disorders Identification Test (AUDIT): WHO collaborative project on early detection of persons with harmful alcohol consumption--II. Addiction 1993;88:791-804.

19. Hill TD, Burdette AM, Ellison CG, Musick MA. Religious attendance 
and the health behaviors of Texas adults. Prev Med 2006;42:309-12.

20. Luczak SE, Prescott CA, Dalais C, Raine A, Venables PH, Mednick SA. Religious factors associated with alcohol involvement: results from the Mauritian Joint Child Health Project. Drug Alcohol Depend 2014;135:37-44

21. Kang Sim DE, Hofstetter CR, Irvin VL, Ayers JW, Macera CA, Ji M, et al. Do christian denominations exhibit higher rates of alcohol consumption?: a study of Korean American women in California. J Relig Health 2013;52:285-98.

22. Tuck A, Robinson M, Agic B, Ialomiteanu AR, Mann RE. Religion, al- cohol use and risk drinking among Canadian adults living in Ontario. J Relig Health 2017;56:2023-38.

23. Scheuermann R. Alcoholic drinks and drinking (Buddhism). In: Sarao KT, Long JD, editors. Buddhism and Jainism. Dordrecht, Springer Netherlands; 2017. p. 69-71.

24. Garcia G, Ellison CG, Sunil TS, Hill TD. Religion and selected health behaviors among Latinos in Texas. J Relig Health 2013;52:18-31.

25. VanderWeele TJ. Causal effects of religious service attendance? Soc Psychiatry Psychiatr Epidemiol 2017;52:1331-6. 